\title{
Development and psychometric evaluation of a new tool for measuring the attitudes of patients with progressive neurological diseases to ethical aspects of end-of-life
} care

\author{
Radka Bužgová* and Radka Kozáková
}

\begin{abstract}
Background: Knowing the opinions of patients with Progressive Neurological Diseases (PNDs) and their family members on end-of-life care can help initiate communication and the drawing up of a care plan. The aim of this paper is to describe the creation and psychometric properties of the newly developed APND-EoLC questionnaire (the Attitudes of Patients with Progressive Neurological Disease to End of Life Care questionnaire).
\end{abstract}

Methods: Following focus group discussion, four main areas of interest were identified: patients' and family members' attitudes towards end-of-life care, factors influencing decisions about treatment to prolong patients' life, concerns and fears regarding dying, and opinions on the system of care. The created questions were divided into domains based on factor analysis and psychometric properties were evaluated by sample of 209 patients with PND and 118 their family members.

Results: The final version of the scale contains a total of 28 questions divided into six domains (end-of-life control, keeping patients alive, trust in doctors/treatment, trust in social support, sense of suffering, and dependence/loss of control) and five individual questions determining views of the care system with specified response options. Construct validity was verified by confirmatory factor analysis for each evaluated area individually. Appropriate psychometric properties were identified in the questionnaire.

Conclusions: The APND-EOLC questionnaire can be recommended for use in both research and clinical practice.

Keywords: Attitudes, Care, End of life, Neurology, Reliability, Validity

\section{Background}

Over the past 10 years, there has been increasing professional interest in the provision of quality end-of-life care in patients with progressive neurological diseases (PND), and studies regarding the implementation of palliative care in neurology [1-10], or more specifically in the care

\footnotetext{
* Correspondence: radka.buzgova@osu.cz

Department of Nursing and Midwifery, Faculty of medicine, University of Ostrava, Ostrava, Czech Republic
}

of patients with Parkinson's disease (PD) [11-13], motor neuron disease (MND) [14, 15], and multiple sclerosis (MS) [16-18], have been published.

In 2008, The European Association for Palliative Care, together with the European Academy of Neurology (EAN) initiated the first discussions about the development of palliative care in patients with neurological disease with the aim of improving cooperation between

C C The Author(s). 2020 Open Access This article is licensed under a Creative Commons Attribution 4.0 International License, which permits use, sharing, adaptation, distribution and reproduction in any medium or format, as long as you give appropriate credit to the original author(s) and the source, provide a link to the Creative Commons licence, and indicate if changes were made. The images or other third party material in this article are included in the article's Creative Commons licence, unless indicated otherwise in a credit line to the material. If material is not included in the article's Creative Commons licence and your intended use is not permitted by statutory regulation or exceeds the permitted use, you will need to obtain permission directly from the copyright holder. To view a copy of this licence, visit http://creativecommons.org/licenses/by/4.0/. The Creative Commons Public Domain Dedication waiver (http://creativecommons.org/publicdomain/zero/1.0/) applies to the data made available in this article, unless otherwise stated in a credit line to the data. 
palliative and neurological care providers, and thus to improve care for persons with advanced PND [4].

PND, such as PD, MS, amyotrophic lateral sclerosis (ALS), MND, or Huntington's disease (HD) are characterized by a combination of movement disorders, cognitive function disorders, emotional, and behavioral disorders with varying rapid progression [6]. They can also affect individuals of productive age. They are a diverse group of patients with varying dynamics of gradual deterioration.

As part of the AZV MZ ČR project "Neuropalliative and Rehabilitation Care in Patients with Progressive Neurological Disease", focus groups were organized with the aim of integrating this model into the current system of provision of health and social care to these patients [19]. Since patients, family members, and professionals have different views of how patients with PND and their family members perceive end-of-life care (EoLC), we decided to create a questionnaire identifying the ethical aspects of end-of-life care, including opinions and attitudes of patients with PND and their family members to healthcare provision in the advanced stages of the disease. After a review of the literature, we discovered that there are few available measuring tools to determine PND patients' views on and attitudes to end-of-life care.

A large proportion of end-of-life care assessment tools focus on assessing attitudes to care/ treatment (pain management, end-of-life decision-making, previously expressed wishes, euthanasia, assisted suicide, end-of-life nutrition, and communication) from the doctors' perspective [20], reflecting doctors' attitudes to end-of-life law [21], and doctors' attitudes toward hastened death [22] or palliative sedation [23, 24]. In addition, there are studies focusing on assessment of nursing students' attitudes to end-of-life care [25-27], in which students' attitudes are identified using the Frommelt Attitudes towards Care of the Dying Part B Scale", a 30-item scale (15 positive and 15 negative attitudes) in which respondents agree/disagree with each attitude on a five-point scale.

Clarke et al. [28] investigated preferences of the public to end-of life issues in cases of loss of cognitive/decision-making abilities in Great Britain and the USA. The authors created their own questionnaire in which they determined public opinion of maintaining life at any cost versus assistance in peaceful dying in five stages of disease (dementia) progression. In 2005, Catt et al. [29] created the 27-item Attitudes of Older People to End-ofLife Issues (AEOLI). The AEOLI questionnaire assesses attitudes of older people to death, palliative treatment, and hospice care [29] on a five-point Likert Scale, ranging from "strongly agree" to "strongly disagree" in the following areas: decision making, pain, care environment, living wills, euthanasia/physician-assisted suicide, ageism, psychological needs including religious/spiritual, quality versus quantity of life, and societal awareness. Park et al. [30] investigated the attitudes of older people to death and do-not-resuscitate orders in Korea. Hunt et al. [31] investigated the experiences of end-of life care in the elderly and their preferred places of dying.

Only one study was found that evaluated opinions of patients with PND on end-of-life care, for patients with ALS. Ganzini et al. [32] determined ALS patients' attitudes to assisted suicide. Patients and their family members agreed or disagreed with statements regarding the following areas: refusal of life-saving medical treatment (including cardiopulmonary resuscitation, mechanical ventilation, feeding tubes, and use of adequate medication for pain) even if death was hastened as a result; attitudes to euthanasia; and attitudes to assisted suicide. The created questionnaire was not validated.

The aim of this paper is to describe the development and psychometric properties of a newly created questionnaire for the evaluation of views on and attitudes to ethical aspects of end-of-life care.

\section{Methods}

\section{Questionnaire development}

The APND-EoLC (The Attitudes of Patients with Progressive Neurological Disease to End-of-Life Care Questionnaire) was created in four individual phases (see Fig. 1):

1. The purpose of first phase was identified a problematic issues of end of life care for domains and items generation. The first phase included a individual in-depth interviews with PND's patients (four with severe MS, six with severe PS), family members of PND's patients (two with MS, one with $\mathrm{PD}$, one with HD, two with MND) and a discussion in focus groups $(n=4)$, consisting of 31 health and social care workers (doctors, nurses, physiotherapists, occupational therapists, psychologists, and social workers), two hospital chaplains, and two patients - one with MS, one with PD). The selection of the participants was intentional, and based on the stated criteria: 1) a patient, or family member of a patient with a specific neurological disease (multiple sclerosis, Parkinson's disease, atypical parkinsonism, Huntington's disease, motor neuron disease), at least 1 year after the diagnosis was made, age $>18$ years, MMSE $\geq 24$ points, informed consent in writing; 2) professionals - professional qualification for the given position, at least 1 year's experience of providing care to patients with neurological disease. The data collection formed part of a qualitative study for the research project run by the Czech Ministry of Health (no. 17-29,447) entitled 


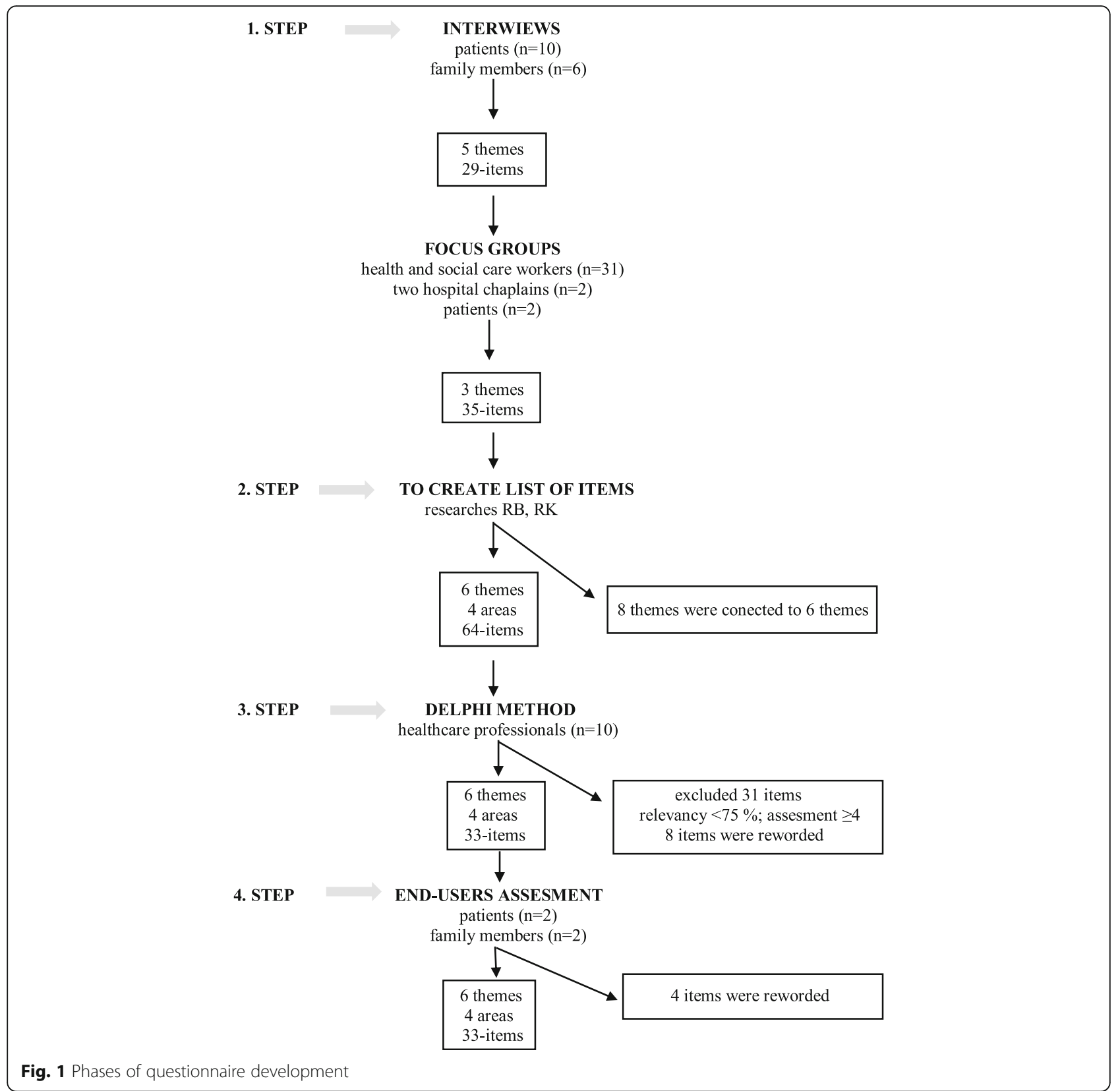

"Neuro-palliative and Rehabilitation Approach to Maintaining Quality of Life of Patients in Advanced Stages of Specific Neurological Diseases". The participants were contacted in all regions of the Czech Republic. The method of obtaining the sample was the snow ball technique. The experiences of the participants with the specific topic was emphasized.

The topic of discussion was the introduction of the concept of neuropalliative and rehabilitative care in patients with PNDs in the Czech Republic, including endof-life care in patients with PND.
First, individual interviews were conducted with patients $(n=10)$ and family members $(n=6)$. The reason for the individual interviews was the preference of patients and family members for the individual conversation, not participation in the focus group. The individual interviews lasted 30 to $70 \mathrm{~min}$. Problematic ethical issues of the end of life (decision making, dying, fear, information, end of life control) identified by patients and family members in individual interviews were categorized into 35 items and subsequently submitted to focus groups. Participants of focus groups talked about the topics presented and categorized items and subsequently identified other potential topics (a place of end of life care, trust, 
awareness $)$ and items $(n=29)$. The length of the focus group was $120 \mathrm{~min}$.

All interviews and focus groups were recorded on a voice recorder and then literally transcribed. The acquired data were then organized and described in detail through thematic analysis. The thematic analysis is based on moving back and forth among the individual data segments, among the extracts, and data codes, and their analysis. The analysis was performed in five phases [33]: 1. acquainting with the data - two researchers (RB, RK) independently codified the raw transcript; 2 . generating initial codes; 3 . theme search - analysis of codes and data to suggest wider meaning patterns (potential themes - end-of-life treatment and care, decision-making and influencing factors, fear of dying); 4. elaborating the topics and their revision; 5.defining and naming the themes (four themes; 64 sub-themes).

2. In the second phase, the questionnaire itself was created. The purpose of the second phase was to obtain a list of possible items to include in the instrument. Based on focus group analysis, two researchers (RB and RK) anticipated problematic end-of-life care issues (end-of-life treatment and care, decision-making and influencing factors, fear of dying), identified areas, and designed individual areas and items (four areas, 6 themes, 45 individual items). Six themes were potential domains.

3. In the final phase, the Delphi method was used to determine expert consensus. The questionnaire was distributed to other selected healthcare professionals from clinical practice $(n=10)$, who expressed their views on the included questions. This expert panel of professionals was formed according to the following criteria: the minimum of 3 years experience with PND's patients, working with neurology patients in health or social institutions in Czech republic. This ensured content validity of the scale.

Selected experts were sent a questionnaire with individual items whose relevance for assessing attitudes to ethical aspects of end-of-life care was established on a 5point scale: 1 (the least relevant) -5 (the most relevant) and one open question for comments. A final version of the questionnaire included items with an expert agreement of at least $75 \%$ (rating $\geq 4$ ). In total, 33 items were included in the final version of the questionnaire ( 28 scale items on a ten-point scale and five items with a specified response option). Now, each comment was reviewed for this pertinence by researchers $\mathrm{RK}$ and $\mathrm{RB}$ and through consensus was reworded when judged appropriate (8 items).
4. Next, researchers RB and RK created the final version of the questionnaire, containing the most frequently preferred questions grouped in four selected areas. Items were further refined based on feedback from experts. The tool was then handed out to the original two patients and two family members for final comments, which were then considered by the authors before making final revisions. The purpose of this last step was to ensure the face validity of the final set of items with the target population of end-users. Face validity is the "degree that end users judge that the items of an assessment instrument are appropriate to the targeted construct and assessment objectives [34]. Selected patients and family members were interviewed on the appropriate construct and understanding and clarity of the items. Four items were reworded.

Then, the questionnaire was then administered to selected family members and PND patients to test its psychometric properties (see the sample). The final version of The APND-EoLC (The Attitudes of Patients with Progressive Neurological Disease to End-of- Life Care Questionnaire) is in additional file 1.

\section{Psychometric evaluation Sample}

Patients and family members meeting the following criteria were included in the research: a patient or a family member of a patient with selected PND (MS, PD, atypical Parkinsonism, HD), at a minimum of 6 months after diagnosis, age $>18$ years, and Mini-Mental State Examination MMSE $\geq 24$ points. The total sample consisted of 327 participants (209 patients with PNDs, and 118 family members).

The study conformed to the provisions of the Declaration of Helsinki, and was approved by the ethics committees of University Hospital Ostrava (no. 486/2016). All subjects gave their informed consent to inclusion before they participated in the study.

\section{Data analysis}

The data were processed using the SPSS v. 21 program. For evaluation of the psychometric properties of the questionnaire, an item analysis of the individual scales was performed, their internal consistency (Cronbach's alpha) and the correlation between the scales (Spearman's correlation coefficient), and items within the scales were determined. To verify construct validity, exploratory factor analysis by principal component method with Varimax rotation, was used. Prior to factor analysis, the suitability of this procedure was verified using the Kaiser-Meyer-Olkin (KMO) test, and Bartlett's test of 
sphericity. The criteria used to find the best fitting structure and the right number of factors were Eigenvalues greater than 1.0, Cattell's Scree Test, a factor loading cut-off of 0.30, the percentage of total variance explained, and the plausibility of the factorial solution.

Internal consistency was determined using Cronbach's alpha $(\alpha)$. While $\alpha>0.70$ is usually stated as an acceptable minimum [35, 36], Streiner and Norman [37] state an acceptable minimum value of $\alpha=0.65-0.70$. This criterion was also used in our research. We also evaluated Cronbach's alpha for the domain without an item. If it was higher than a domain score, the item could be reassigned to another domain. Additionally, item-total correlation was performed. We considered the value $r>$ 0.40 to be an acceptable minimum [38]. For all analyses, two-tailed $p$ values $<0.05$ were considered significant.

\section{Results}

\section{APND-EoLC questionnaire}

For the final version of the APND-EoLC (The Attitudes of Patients with Progressive Neurological Disease to Endof-Life Care questionnaire) 28 scale questions (items) were selected to establish participants' views and attitudes on a ten-point scale, and for five items participants could choose from specified response options. The questions were divided into four individual areas:

I. A scale determining patients' and family members' attitudes to end-of-life care (end-of-life control, keeping a patient alive, trust in doctors) - 12 items with a ten-point scale: 1 (totally disagree) - 10 (absolutely agree).

II. A scale determining factors influencing decisionmaking regarding life-saving treatment - seven items with a ten-point scale: 1 (not at all) -10 (to a great extent).

III. A scale determining concerns and fear of dying nine items with a ten-point scale: 1 (not at all) -10 (to a great extent).

IV. Questions determining views of the care system awareness, persons making decisions about end-oflife care, and the place of care provision (five questions with specified response options).

The questionnaire was evaluated in separate individual areas. In areas $1-3$, domain scores were evaluated. The questions were divided into domains based on factor analysis. The domain score was calculated as the sum of answers to all questions in the domain divided by the number of questions in the domain, and then converted to a 10-100 scale. In area four, individual questions were evaluated separately. Versions of the questionnaire for patients (APND-EoLC_p) and for family members (APND-EoLC_fam) were created. The purpose of the family questionnaire was to assess their own attitudes in this area. Using similarly formulated questions for patients and their family members, questionnaires can be used to compare attitudes to ethical aspects of end-oflife care in patients and their families. This may open a subsequent discussion on these topics when communicating with the patient and their family.

\section{Socio-demographic characteristics of the sample}

A total of 209 patients with PND (MS: $n=133$, PD: $n=$ 69, HD: $n=7$ ) and 118 family members (MS: $n=40$, PD: $n=65$, HD: $n=12$ ) participated in the research. The patients' average age was 55.1 years $(\mathrm{s}=16.4 ;$ min-max: 19-91). The family members' average age was 54.5 years ( $\mathrm{s}=14.8$; min-max: $21-84)$. A total of 94 family members of patients also completed the questionnaire. Other socio-demographic factors are given in the Table 1.

\section{Evaluation of construct validity and reliability}

Construct validity was verified by exploratory factor analysis for each evaluated area individually. Factor analysis was always performed for a group of patients and family members.

\section{Area l.: scales identifying attitudes to end-of-life care}

Satisfactory values of $\mathrm{KMO}=0.771$ in the sample of patients, and $\mathrm{KMO}=0.709$ in the sample of family members were found, meaning use of factor analysis was valid. The suitability of the use of factor analysis was also confirmed by Bartlett's test of sphericity (patient sample: chí $^{2}=655.670 ; \mathrm{Df}=66 ; p<0.001$; family member sample: $\mathrm{chí}^{2}=573.925 ; \mathrm{Df}=66 ; p<0.001$ ). Additionally, we determined communality after factor extraction. Variability of variables is explained by factor analysis from 21 to $26 \%$. Factor analysis included factors whose dispersion was greater than 1 . All items of two factors loaded above 0.30 .

Exploratory factor analysis of all items in this area divided answers into two different factors (Table 2) in the sample of patients and family members. The first factor, which explains $27 \%$ variation ( $25 \%$ in the sample of family members), was called "control over end-of life". It focused on attitudes related to the possibility of influencing the end of life, with an emphasis on its quality rather than length. The second factor, explaining $21 \%$ of variation, was called "keeping patients alive", and included attitudes related to saving life and the emphasis put on a doctor taking responsibility for the management of end-of-life care. For the "control over end-oflife" scale, Cronbach's alpha $=0.652$ (respectively $0.659-$ sample of family members); while for the "keeping patients alive" scale, Cronbach's alpha $=0.658$ (respectively 0.695 - sample of family members). 
Table 1 Socio-demographic Characteristics of the Sample

\begin{tabular}{|c|c|c|c|c|c|}
\hline & Patients & Family & & Patients & Family \\
\hline & $N=209$ & $N=118$ & & $N=209$ & $N=118$ \\
\hline Sex - N (\%) & & & Job - N (\%) & & \\
\hline Man & $74(35)$ & $53(45)$ & Employed & $54(26)$ & $60(51)$ \\
\hline Woman & $135(65)$ & $65(55)$ & Student & $2(1)$ & $2(2)$ \\
\hline Education N (\%) & & & On maternity leave/at home & $3(1)$ & $5(4)$ \\
\hline Elementary & $13(6)$ & $7(6)$ & Invalid pensioner & $78(38)$ & $7(6)$ \\
\hline Secondary & $162(78)$ & $79(67)$ & Old-age pensioner & $69(33)$ & $43(36)$ \\
\hline Tertiary & $34(16)$ & $32(27)$ & Unemployed & $3(1)$ & $1(1)$ \\
\hline Children - yes N (\%) & $175(84)$ & $94(80)$ & Duration of disease - N (\%) & & \\
\hline Marital status - N (\%) & & & Less than a year & $8(4)$ & - \\
\hline Single & $32(15)$ & $18(15)$ & $1-3$ yrs & $27(13)$ & - \\
\hline Married & $125(60)$ & $83(70)$ & $4-6$ yrs & $40(19)$ & - \\
\hline Divorced & $31(15)$ & $16(14)$ & $7-10$ yrs & $29(14)$ & - \\
\hline Widow/er & $21(10)$ & $1(1)$ & More than $10 \mathrm{yrs}$ & $105(50)$ & - \\
\hline Relationship N (\%) & & & Contribution to care - N (\%) & & \\
\hline Husband/wife & - & $58(49)$ & None & $114(55)$ & - \\
\hline Partner & - & $8(7)$ & । & $25(12)$ & - \\
\hline Son/daughter & - & $29(25)$ & $\|$ & $25(12)$ & - \\
\hline Mother/father & - & $8(7)$ & III & $36(17)$ & - \\
\hline Other & - & $15(12)$ & IV & $9(4)$ & - \\
\hline
\end{tabular}

Table 2 Exploratory Factor Analysis of Items in Area 1: "Attitudes to end-of-life care"

\begin{tabular}{|c|c|c|c|c|c|c|}
\hline \multicolumn{7}{|l|}{ Rotated Component Matrix ${ }^{a}$} \\
\hline \multirow[t]{2}{*}{ Attitudes } & \multicolumn{3}{|c|}{ Patients } & \multicolumn{3}{|c|}{ Family members } \\
\hline & 1 & 2 & $\begin{array}{l}a^{b} \\
a^{c}\end{array}$ & 1 & 2 & $\begin{array}{l}a^{b} \\
a^{c}\end{array}$ \\
\hline Dom 1 - CONTROL OVER END OF LIFE & & & 0.652 & & & 0.659 \\
\hline Having medicine available to end one's life. & & 0.648 & 0.537 & & 0.554 & 0.471 \\
\hline Quality of life is more important than its length. & & 0.673 & 0.531 & & 0.497 & 0.551 \\
\hline Greater fear of helplessness and dependence than of death. & & 0.752 & 0.479 & & 0.714 & 0.500 \\
\hline Having pain killers under control. & 0.412 & 0.476 & 0.557 & & 0.619 & 0.552 \\
\hline More open discussions in public about death and dying. & 0.340 & 0.346 & 0.609 & & 0.309 & 0.622 \\
\hline Dom 2 - KEEPING PATIENTS ALIVE & & & 0.658 & & & 0.695 \\
\hline Discussion with a doctor about prognosis and end of life is too depressing. & 0.309 & & 0.671 & 0.461 & & 0.645 \\
\hline To have the latest treatment available regardless of the side effects. & 0.537 & & 0.595 & 0.624 & & 0.587 \\
\hline The doctor should decide about and manage end-of-life care. & 0.427 & & 0.622 & 0.323 & 0.316 & 0.612 \\
\hline To have pain relief treatment at the cost of sedation or confusion. & 0.416 & & 0.644 & 0.529 & & 0.650 \\
\hline When losing the ability to eat, to start tube (enteral) feeding. & 0.792 & & 0.652 & 0.672 & & 0.557 \\
\hline When losing the ability to breathe, to introduce APV. & 0.738 & -0.397 & 0.518 & 0.762 & & 0.528 \\
\hline \multirow[t]{2}{*}{ To be kept alive at any cost. } & 0.509 & -0.499 & 0.587 & 0.638 & -0.323 & 0.596 \\
\hline & $26.8 \%$ & $21.4 \%$ & & $25.4 \%$ & $21.1 \%$ & \\
\hline
\end{tabular}


Area II: scales identifying factors that influence decisionmaking

Satisfactory values of $\mathrm{KMO}=0.782$ in the patient sample, and $\mathrm{KMO}=0.714$ in the family member sample were found, meaning use of factor analysis was valid. The suitability of the use of factor analysis was further confirmed by Bartlett's test of sphericity (patient sample: chí $^{2}=664.932$; Df $=21 ; p<0.001$; family member sample: chí $\left.^{2}=283.629 ; \mathrm{Df}=21 ; p<0.001\right)$. Variability of variables is explained by factor analysis from 16 to $52 \%$.

Based on factor analysis, the items were divided into two factors (domains): "trust in the doctor/treatment", and "trust in social support". Reliability of the scale was found to be satisfactory, i.e. $\alpha>0.65$ (Table 3).

\section{Area III: "Scales Identifying Fear of Dying"}

In the third area, the suitability of the use of factor analysis was also confirmed (patients: $\mathrm{KMO}=0.861$ chí $^{2}=$ 841.136; $\mathrm{Df}=36 ; p<0.001$; family members: $\mathrm{KMO}=0$, 835 chí $^{2}=525.960$; Df $\left.=21 ; p<0.001\right)$. Variability of variables is explained by factor analysis from 13 to $51 \%$. The first factor explained 51\% variation in both samples and it combines items ascertaining fear and concerns about one's own suffering (see Table 4). Reliability of the scales in this area was also found to be satisfactory.

After the exploratory factor analysis all proposed items $(n=33)$ were left in the questionnaire. The structure of the created questionnaire is shown in Fig. 2.

Table 3 Exploratory Factor Analysis of Items in Area II: "Factors influencing decision-making"

\begin{tabular}{|c|c|c|c|c|c|c|}
\hline \multicolumn{7}{|l|}{ Rotated Component Matrix ${ }^{a}$} \\
\hline \multirow[t]{2}{*}{ Attitudes } & \multicolumn{3}{|c|}{ Patients } & \multicolumn{3}{|c|}{ Family members } \\
\hline & 1 & 2 & $\begin{array}{l}a^{b} \\
a^{c}\end{array}$ & 1 & 2 & $\begin{array}{l}a^{b} \\
a^{c}\end{array}$ \\
\hline $\begin{array}{l}\text { Dom } 3 \text { TRUST IN THE } \\
\text { DOCTOR/TREATMENT }\end{array}$ & & & 0.852 & & & 0.804 \\
\hline $\begin{array}{l}\text { vDoctor's } \\
\text { recommendation }\end{array}$ & 0.872 & & 0.815 & 0.833 & & 0.734 \\
\hline $\begin{array}{l}\text { More doctors' } \\
\text { consensus }\end{array}$ & 0.901 & & 0.828 & 0.869 & & 0.760 \\
\hline $\begin{array}{l}\text { Hope of a better quality } \\
\text { of life }\end{array}$ & 0.643 & 0.536 & 0.801 & 0.7795 & & 0.722 \\
\hline Hope of prolonging life & 0.622 & 0.322 & 0.801 & 0.617 & 0.381 & 0.804 \\
\hline $\begin{array}{l}\text { Dom } 4 \text { TRUST IN SOCIAL } \\
\text { SUPPORT }\end{array}$ & & & 0.652 & & & 0.679 \\
\hline $\begin{array}{l}\text { The approval of the } \\
\text { closest family }\end{array}$ & & 0.358 & 0.584 & & 0.608 & 0.592 \\
\hline $\begin{array}{l}\text { Information from mass } \\
\text { media and the Internet }\end{array}$ & & 0.822 & 0.532 & & 0.835 & 0.621 \\
\hline \multirow{2}{*}{$\begin{array}{l}\text { Other patients' } \\
\text { experiences }\end{array}$} & 0.376 & 0.740 & 0.399 & 0.399 & 0.637 & 0.507 \\
\hline & $52.1 \%$ & $15.9 \%$ & & $45.4 \%$ & $17.8 \%$ & \\
\hline
\end{tabular}

a Varimax with Kaiser Normalization, Coefficients below 0.3 suppressed,

${ }^{b}$ Cronbach's alpha for domain, 'Cronbach's alpha if item deleted
Table 4 Exploratory Factor Analysis of Items in Area III: "Fear of dying"

\begin{tabular}{|c|c|c|c|c|c|c|}
\hline \multicolumn{7}{|l|}{ Rotated Component Matrix ${ }^{a}$} \\
\hline \multirow[t]{2}{*}{ Attitudes } & \multicolumn{3}{|c|}{ Patients } & \multicolumn{3}{|c|}{ Family members } \\
\hline & 1 & 2 & $\begin{array}{l}a^{b} \\
a^{c}\end{array}$ & 1 & 2 & $\begin{array}{l}a^{b} \\
a^{c}\end{array}$ \\
\hline $\begin{array}{l}\text { Dom } 5 \text { - ONE'S OWN } \\
\text { SUFFERING }\end{array}$ & & & 0.828 & & & 0.822 \\
\hline Severe pain & 0.702 & & 0.812 & 0.618 & & 0.818 \\
\hline Loneliness & 0.780 & & 0.799 & 0.796 & & 0.765 \\
\hline Choking, dyspnea & 0.678 & 0.388 & 0.789 & 0.819 & & 0.774 \\
\hline Sleep disorders & 0.757 & & 0.786 & 0.554 & 0.376 & 0.799 \\
\hline Loss of ability to eat & 0.704 & 0.409 & 0.784 & 0.739 & 0.401 & 0.757 \\
\hline \multicolumn{2}{|c|}{$\begin{array}{l}\text { Dom } 6 \text { - DEPENDENCE/LOSS OF } \\
\text { CONTROL }\end{array}$} & & 0.835 & & & 0.759 \\
\hline $\begin{array}{l}\text { Dependence on care of } \\
\text { others }\end{array}$ & & 0.808 & 0.819 & & 0.853 & 0.649 \\
\hline $\begin{array}{l}\text { Loss of control over } \\
\text { oneself }\end{array}$ & 0.324 & 0.774 & 0.775 & & 0.761 & 0.746 \\
\hline $\begin{array}{l}\text { Decreased mental } \\
\text { abilities }\end{array}$ & 0.435 & 0.678 & 0.803 & 0.316 & 0.445 & 0.675 \\
\hline \multirow[t]{2}{*}{ Being a burden to others } & & 0.836 & 0.770 & & 0.910 & 0.730 \\
\hline & $51.1 \%$ & $13.2 \%$ & & $50.8 \%$ & $15.9 \%$ & \\
\hline
\end{tabular}

avarimax with Kaiser Normalization, Coefficients below 0.3 suppressed,

${ }^{b}$ Cronbach's alpha for domain, 'Cronbach's alpha if item deleted

\section{Correlation analysis \\ Item-Total correlation}

The suggested minimum standard for item-to-scale total consistency is a correlation of at least 0.40 between the scale and each item. The correlation coefficient $\mathrm{r}<0.40$ was found in domain 1 in the item "More open discussions in public about death and dying" (patients: $r=$ 0.322 , family: $r=0.269$ ) and in domain 2 in the item "Discussion with a doctor about prognosis and end of life is too depressing" (patients: $\mathrm{r}=0.313$, family: $\mathrm{r}=0.220$ ), see Table 5 .

Correlation analysis showed that only some domains were highly inter-correlated (Table 6).

\section{Discussion}

In recent decades, research into end-of-life care of patients with progressive neurological disease has flourished. However, in a review of the literature, no evaluation scales identifying views of PND patients on end-of-life issues were found. For this reason, we developed a tool in order to evaluate attitudes towards ethical aspects of end-of-life care for patients with PND, and their family members. The main finding of this study was to demonstrate the adequate psychometric characteristics of the Attitudes of Patients with PND to Endof-Life Care questionnaire in the population of patients with PNDs, and their family members. Determining opinions on ethical issues to end-of-life care can help 
Table 5 Item-Total Correlation of APND-EoLC Domains

\begin{tabular}{|c|c|c|c|c|c|c|c|}
\hline & Domains & Patient & & & Family & & \\
\hline & & Mean & SD & Item-Total & Mean & SD & Item-total \\
\hline Dom 1 & End-of life control & 75.5 & 17.5 & $0.322-0.482$ & 67.3 & 15.9 & $0.269-0.477$ \\
\hline Dom 2 & Keeping a patient alive & 59.3 & 17.5 & $0.313-0.568$ & 68.8 & 14.9 & $0.220-0.498$ \\
\hline Dom 3 & Trust in doctor/treatment & 69.4 & 24.4 & $0.661-0.724$ & 78.8 & 20.5 & $0.559-0.709$ \\
\hline Dom 4 & Trust in social support & 50.8 & 21.4 & $0.426-0.495$ & 76.7 & 80.0 & $0.467-0.545$ \\
\hline Dom 5 & One's own suffering & 67.1 & 22.2 & $0.562-0.664$ & 75.6 & 18.4 & $0.454-0.710$ \\
\hline Dom 6 & Dependence/loss of control & 79.3 & 21.4 & $0.604-0.721$ & 79.2 & 21.4 & $0.475-0.654$ \\
\hline
\end{tabular}

physicians, patients, and family members to develop individual care plans. Due to frequent cognitive, emotional and behavioral disorders in patients with PND [6, 39], it is advisable to establish these views in the first stages of the disease. For this reason, patients with a selected disease were included in the group 1 year after diagnosis.

Based on the individual interviews and the focus group discussion, four major areas of interest were identified: namely patient and family attitudes towards end-of-life care, factors influencing decisions about life-sustaining treatment, concerns and fears of dying, and opinions on the care system. Scale questions were not used in the last area. For this reason, the psychometric properties were evaluated only in the first three areas, where satisfactory reliability of all scales was established. In the first area of the end-of-life attitudes survey, we created two domains using factor analysis: end-of-life control and keeping patients alive. The option of being able to decide on treatment preferences is cited by Steinhauser et al.
[40] in his study as an important area of care at the endof-life, both from the point of view of patients and their family members, and from doctors and other health care professionals (nurses, social workers, chaplains). Control over the end of life is associated with an important principle of current medical ethics: the principle of autonomy [41].

The right to autonomy implies that a patient, when she/he is competent, has the right to exercise her/his preference for or refusal of treatment, except in circumstances, (for example, contagious disease) in which refusal may cause harm to others. This can be regarded as respect for contemporaneous choice (or contemporary autonomy). Competent patients may also want to make a choice about future contingencies, including those in which they will not be able to decide for themselves e.g., when they lapse into incompetency [42]. Collating endof-life treatment options makes it possible to preformulate the wishes of patients and their family. Using

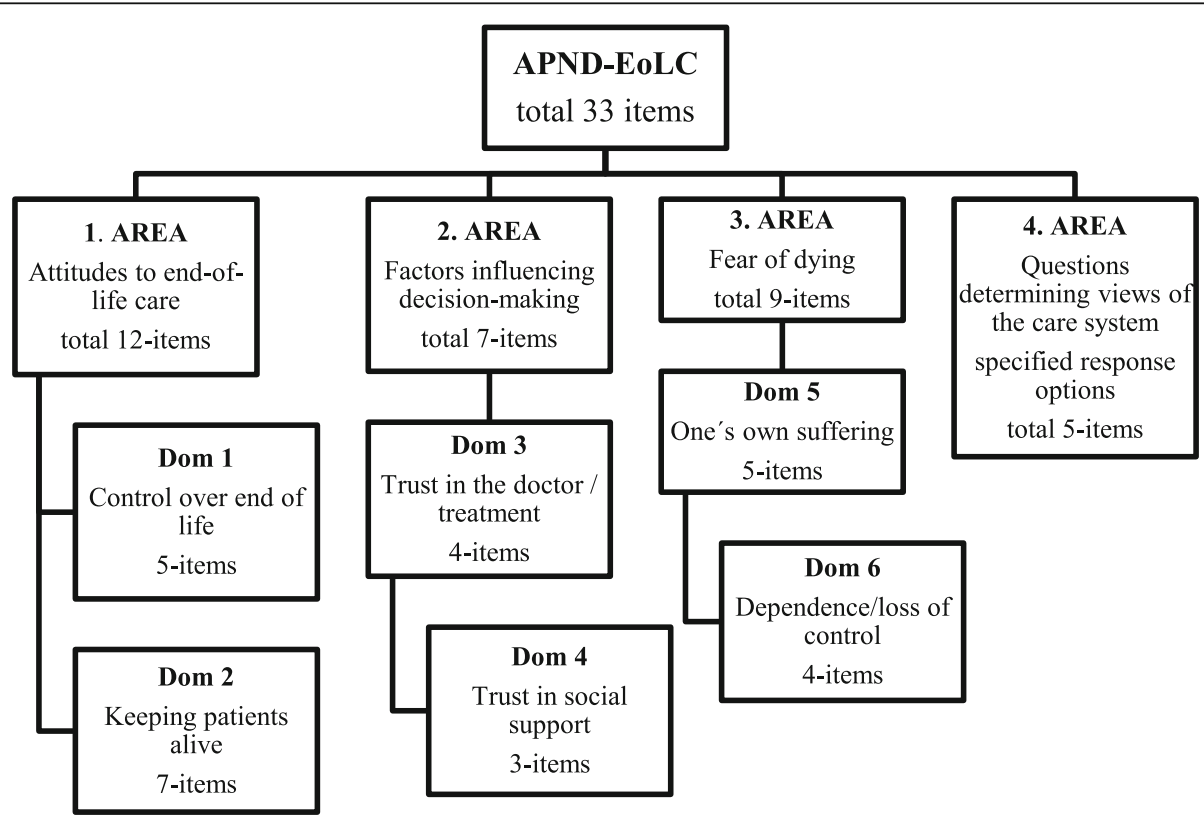

Fig. 2 Structure of the APND-EoLC questionnaire 
Table 6 Inter-Domain Correlations (Spearman) of APND-EoLC

\begin{tabular}{|c|c|c|c|c|c|c|c|c|c|c|c|c|}
\hline \multirow[b]{2}{*}{$P$} & \multicolumn{6}{|c|}{ PATIENTS (P) } & \multicolumn{6}{|c|}{ FAMILY MEMBERS (FM) } \\
\hline & Dom1 & Dom2 & Dom3 & Dom4 & Dom5 & Dom6 & Dom1 & Dom2 & Dom3 & Dom4 & Dom5 & Dom6 \\
\hline Dom1 & 1.000 & -0.099 & -0.087 & $-0.167^{*}$ & $0.205^{* *}$ & $0.314^{* *}$ & $0.436^{* *}$ & 0.028 & 0.028 & 0.106 & 0.098 & $0.314^{* *}$ \\
\hline Dom2 & -0.099 & 1.000 & $0.484^{* *}$ & $0.299^{* *}$ & $0.188^{* *}$ & 0.020 & -0.004 & $0.442^{* *}$ & 0.185 & 0.138 & 0.160 & 0.020 \\
\hline Dom3 & -0.087 & $0.484^{* *}$ & 1.000 & $0.512^{* *}$ & $0.278^{* *}$ & $0.194^{* *}$ & 0.028 & -0.027 & $0.306^{* *}$ & 0.164 & 0.177 & $0.194^{*}$ \\
\hline Dom4 & $0.167^{*}$ & $0.299^{* *}$ & $0.512^{* *}$ & 1.000 & $0.181^{*}$ & -0.015 & -0.075 & 0.076 & 0.175 & 0.074 & 0.079 & $-0,015$ \\
\hline Dom5 & $0.205^{* *}$ & $0.188^{* *}$ & $0.278^{* *}$ & $0.181^{*}$ & 1.000 & $0.598^{* *}$ & 0.098 & -0.080 & 0.178 & $0.430^{* *}$ & $0.449^{* *}$ & $0.598^{* *}$ \\
\hline Dom6 & $0.314^{* *}$ & 0.020 & $0.194^{* *}$ & -0.015 & $0.598^{* *}$ & 1.000 & 0.197 & -0.040 & $0.246^{* *}$ & $0.321^{* *}$ & $0.356^{* *}$ & $0.948^{* *}$ \\
\hline \multicolumn{13}{|l|}{ FM } \\
\hline Dom1 & $0.436^{* *}$ & -0.004 & 0.028 & -0.075 & 0.098 & 0.197 & 1.000 & -0.030 & -0.040 & 0.181 & 0.174 & 0.197 \\
\hline Dom2 & 0.028 & $0.442^{* *}$ & -0.027 & 0.076 & -0.080 & -0.040 & -0.030 & 1.000 & $0.216^{*}$ & 0.149 & 0.111 & -0.040 \\
\hline Dom3 & 0.028 & 0.185 & $0.306^{* *}$ & 0.175 & 0.178 & $0.246^{* *}$ & -0.040 & $0.216^{*}$ & 1.000 & $0.319^{* *}$ & $0.332^{* *}$ & $0.246^{* *}$ \\
\hline Dom4 & 0.106 & 0.138 & 0.164 & 0.074 & $0.430^{* *}$ & $0.321^{* *}$ & 0.181 & 0.149 & $0.319^{* *}$ & 1.000 & $0.961^{* *}$ & $0.321^{* *}$ \\
\hline Dom5 & 0.098 & 0.160 & 0.177 & 0.079 & $0.449^{* *}$ & $0.356^{* *}$ & 0.174 & 0.111 & $0.332^{* *}$ & $0.961^{* *}$ & 1.000 & $0.356^{* *}$ \\
\hline Dom6 & $0.314^{* *}$ & 0.020 & $0.194^{*}$ & $-0,015$ & $0.598^{* *}$ & $0.948^{* *}$ & 0.197 & -0.040 & $0.246^{* *}$ & $0.321^{* *}$ & $0.356^{* *}$ & 1.000 \\
\hline
\end{tabular}

the APND-EoLC questionnaire in clinical practice can help doctors "open" these topics with patients and family members.

However, Haškovcová [43] points out that the patients' authoritative and unlimited autonomy cannot always be exercised in the process of dying. She understands the right to self-determination as a human right, which is mainly related to the dignity and freedom of a human being. However, no right can be exercised recklessly and without correlations. The exaggerated emphasis on the patient's autonomous behavior negates the fact that the patient makes their wishes and judgments under the weight of their difficult situation. Some authors point to other ethical approaches, such as the ethics of care [44]. The ethics of care usually works with a conception of persons as relational, rather than as the self-sufficient independent individuals of the dominant moral theories [44]. It is a philosophical perspective that focuses on the unique ethical dimension of close relationships, emphasizes relationships over rules and principles [45]. The ethics of care emphasizes the vulnerability and interdependence of human beings. It concludes that ethics should not only deal with decision-making, but also the quality of relationships, e.g. in terms of continuity, openness, trust and reliability [44]. Open communication with the patient, health care professionals and family members about the end of life care can also be based on a mutual relationship.

If caregivers listen to the narratives of identity of patients, and engage in a deliberative dialogue they will better be able to attune their care to the needs of patients $[46,47]$. Narrative gives a peculiar insight into the reality of others' lives that enhances our understanding. Baldwin [48] talks about a narratively informed decision- making. Based on a systematic review, Winterbottom [49] points out that narrative information influenced decision making more than the provision of no additional information and/or statistically based information in approximately a third of the studies.

In the second area, we identified factors that can influence decision-making at the end of life. Two domains were identified: trust in a doctor/treatment (including questions about doctors' recommendations, hope of better quality of life, and prolongation of life), and social support (including questions aimed at surrounding support - family, other patients, or media). How the support of doctors, health professionals or loved ones can influence the decision-making process is being established in this domain. Bergum and Dossetro [50] talk about socalled Relational ethics. The basic premise of relational ethics is that ethical decisions/actions are made within the context of a relationship. The fundamental nature of relational ethics is that ethical commitment, agency, and responsibility for self and to the other arises out of concrete situations which invariably involve relations between two or more people and affect two or more people [51].

The decision not to provide life-saving medical treatment is a complex, emotionally-charged and contentious issue for the patient, medical team, and family alike [52]. Evidence shows that, too often, patients' wishes about their medical treatment at the end of life are not known by their doctors and/or families [53]. One reason for this is that our culture is predominantly 'death denying' [54, 55]. Discussing death and end-of-life issues may be uncomfortable, and is sometimes taboo. It is recommended that the physician responsible for overall patient care and treatment initiate a discussion about care planning 
shortly after diagnosing a life-threatening disease or condition. According to Detering et al. [53], and Teno et al. [56], evidence shows that providing good end-of-life care leads to better quality-of-life for patients before death.

In the third area, we identified concerns and fears of dying. We selected two domains, fear of own suffering, and fear of dependence and control over one's life. Dealing with fear of dying is an important part of understanding patients and their family members in the context of their end-of-life care experience. A scale of assessment for fear of death and dying was created by Collett and Lester as early as 1969 [57]. This 28-item scale (The Collett-Lester Fear of Death Scale - CLFODS) has been validated in several cultural contexts, evidencing acceptable psychometric characteristics [5862]. It is mainly used to assess fear of death and dying among healthcare workers in a training context. Fear of dying was identified in patients with acute coronary syndrome [63, 64], and in the elderly [65]. Our questionnaire dealt only with fear of dying, not of death itself. The areas of fear of dying were formulated in nine items, for instance loneliness, dependence, loss of control, burden to others. These areas may be related to spirituality [66], so we recommend finding out religion or spirituality when using the questionnaire.

The fourth area consisted of questions about the place of end-of-life care, and about initiating discussion with a doctor about the end of life and with those who should decide on end-of-life care. In particular, finding the most appropriate place of care is currently a common research subject in different patient groups [31, 67-69], and patients with PND and their family members should not be overlooked.

The APND-EoLC questionnaire can be used in acute and chronic care facilities. It is recommended that it be administered to patients and family members it shortly after diagnosis and then whenever a medical condition deteriorates. The questionnaire should be administered by a nurse. Other healthcare professionals should have access to the questionnaire in the medical records, mainly because of communication about the future care plan with the patient and their family. In social service facilities, the questionnaire should be the basis for the creation of an individual care plan. In social service facilities, planning of the end of life care is regarded as an extension of the individual plan, which supports the autonomy of clients of residential facilities. When planning, clients are asked about ideas and wishes regarding health care, as well as further self-care at the end of their lives [70]. The APND-EoLC questionnaire covers all these areas. It can also be administered by a nurse in social service facilities.

\section{The limits of the study and future research}

In the first phase of creating a questionnaire, a certain limitation of the study is the low participation rate of patients and family members in focus groups. The reason was the patients' and family members' unwillingness to attend a group meeting. For this reason, we conducted individual interviews. On their basis we analyzed potential end-of-life issues from the perspective of patients and family members and presented them to the focus group participants. This could take into account the patients' and family members' perspective when developing the questionnaire. Another limitation of the creation of the questionnaire can be the selection of only two patients and two family members who assessed the understandability of the final version of the questionnaire. However, both patients and family members confirmed the clarity of the questions presented during the interview. Experts or target-population can evaluate the created items. Experts had evaluated individual items in our research earlier than patients and family members (targetpopulation) did. According to Boateng et al. [71] expert judges seem to be used more often than target-population judges in scale development work to date. Ideally, one should combine expert and target population judgment, as was the case in our research (though resources of targetpopulation were constrained).

The limitation of the evaluation of the psychometric properties of the created version of the questionnaire is that we do not use any comparator gold standard instrument. The reason is the lack of a validated tool in Czech for evaluating attitudes to ethical aspects of the end of life. In further research, the Collett-Lester Fear of Death Scale - CL-FODS could be used for area 3. For further research, we also recommend evaluating the tool over time for evidence of test-retest reliability and responsiveness to change. We also recommend testing a confirmatory factor analysis on the next sample of respondents.

\section{Conclusion}

In conclusion, the Czech version of the APND-EoLC questionnaire had good psychometric characteristics when applied to patients with PND and their family members, and can be recommended for use in research and clinical assessment in the Czech Republic. The use of instruments with weak psychometric properties can seriously compromise the credibility of research findings. An English language version has been created for use in other countries. Able to be administered by doctors, nurses and social workers, the APND-EoLC questionnaire could become a suitable tool for determining end of life care plans.

\section{Supplementary information}

Supplementary information accompanies this paper at https://doi.org/10. 1186/s12910-020-00471-9.

Additional file 1 : questionnaire. The APND-EoLC - The Attitudes of Patients with Progressive Neurological Disease to End-of-Life Care Questionnaire. 


\section{Abbreviations}

AEOLI: Attitudes of Older People to End-of-Life Issues; APND-EoLC: The Attitudes of Patients with Progressive Neurological Disease to End-of-Life Care questionnaire; CL-FODS: The Collett-Lester Fear of Death Scale; EoLC: End of life care; EAN: The European Academy of Neurology; HD: Huntington's disease; KMO: The Kaiser-Meyer-Olkin; MMSE: Mini-Mental State Examination; MND: Motor neuron disease; MS: Multiple sclerosis; PD: Parkinson's disease; PND: Progressive neurological diseases

\section{Acknowledgements}

Authors thanks all patients with PND, their family members and health care professionals for their participation in the study.

\section{Authors' contributions}

RB and RK contributed to study design, planning, data collection and data analysis. RB and RK reviewed and approved the manuscript. The author(s) read and approved the final manuscript.

\section{Funding}

The study was supported by the Ministry of Health, Czech republic (grant AZV MZ ČR no. 17-29447A).

\section{Availability of data and materials}

The excel file can be provided on demand. RB (corresponding author) should be contacted by anyone requesting the data.

\section{Ethics approval and consent to participate}

The study conformed to the provisions of the Declaration of Helsinki, and was approved by the ethics committees of University Hospital Ostrava (no. 486/2016). All subjects gave their written informed consent to inclusion before they participated in the study.

\section{Consent for publication}

Not applicable.

\section{Competing interests}

The authors declare no financial or other conflict of interest.

Received: 3 April 2019 Accepted: 7 April 2020

Published online: 15 April 2020

\section{References}

1. Turner-Stokes L, Sykes N, Silber E, Khatri A, Sutton L, Young E. From diagnosis to death: exploring the interface between neurology, rehabilitation and palliative care, in the management of people with long term neurological conditions. Clin Med. 2007:7(2):129-236.

2. Chahine L, Malik B, Davis M. Palliative care needs of patients with neurologic or neurosurgical conditions. Eur J Neurol. 2008. https://doi.org/ 10.1111/j.1468-1331.2008.02319.x.

3. Sutton L. Addressing palliative and end-of-life care needs in neurology. $\mathrm{Br} J$ Neurosci Nurs. 2008. https://doi.org/10.12968/bjnn.2008.4.5.29323.

4. Borasio GD. The role of palliative care in patients with neurological disease. Nat Rev Neurol. 2013. https://doi.org/10.1038/nrneurol.2013.49.

5. Fitzpatrick R, Peters M, Doll H, Harris R, Jenkinson C, Playford D, Ziebland S. The needs and experiences of services by individuals with long-term progressive neurological conditions and their carers. A Benchmarking study. Oxford: University of Oxford; 2010.

6. Hussain J, Adams D, Campbell C. End-of-life care in neurodegenerative conditions: outcomes of a specialist palliative neurology service. Int J Palliat Nurs. 2013. https://doi.org/10.12968/ijpn.2013.19.4.162.

7. Boesma I, Miyasaki J, Kutner J, Kluger B. Palliative care in neurology. Time for a paradigm shift. Neurology. 2014. https://doi.org/10.1212/WNL. 0000000000000674.

8. Dallara A, Tolchin DW. Emerging subspecialties in neurology: palliative care. Neurology. 2014. https://doi.org/10.1212/WNL.0000000000000453.

9. van Vliet LM, Gao W, DiFrancesco D, Crosby V, Wilcock A, Byrne A, et al. How integrated are neurology and palliative care services? Results of a multicentre mapping exercise. BMC Neurol. 2016. https://doi.org/10.1186/ s12883-016-0583-6.
10. Oliver D, Borasio GD, Caraceni A. A consensus review on the development of palliative care for patients with chronic and progressive neurological disease. Eur J Neurol. 2016. https://doi.org/10.1111/ene.12889.

11. Hasson F, George Kernohan W, McLaughlin M, Waldron M, Laughlin DM, Chambers $\mathrm{H}$, Cochrane B. An exploration into the palliative and end-of-life experiences of cares of people with Parkinson disease. Palliat Med. 2010. https://doi.org/10.1177/0269216310371414.

12. Miyasaki JM, Long J, Mancini D, Moro E, Fox SM, Lang AE, Marras CL, Chen R, Strafella AP, Arshinoff R, Ghoche R, Hui JS. Palliative care for advanced Parkinson disease: an interdisciplinary clinic and new scale, the ESAS-PD. Parkinsonism Relat Disord. 2012. https://doi.org/10.1016/j.parkreldis.2012.06. 013.

13. Lindtop F, Brown L, Graziano M, Diana J. Atypical parkinsonism: making the case for a neuropalliative rehabilitation approach. Int J Ther Rehabil. 2014. https://doi.org/10.12968/ijtr.2014.21.4.176.

14. Oliver D. Palliative care for motor neuron disease. Pract Neurol. 2002. https://doi.org/10.1046/j.1474-7766.2002.00402.x.

15. Aoun SM, Connors SL, Priddis L, Breen LJ, Colyer S. Motor Neurone Disease family carers' experiences of caring palliative care and bereavement: An exploratory qualitative study. Palliat Med. 2012. https://doi.org/10.1177/ 026921631141603626(6):842-850

16. Higginson IJ, McCrone P, Hart SR, Burman R, Silber E, Edmonds PM. Is shortterm palliative care cost effective in multiple sclerosis. A randomized phase II trial. J Pain Symptom Manag. 2009. https://doi.org/10.1016/j.jpainsymman. 2009.07.002

17. Edmonds, Polly, Sam Hart, Wei Gao, Bella Vivat, Rachel Burman, Eli Silber, and Irene J Higginson. 2010. Palliative care for people severely affected by multiple sclerosis: evaluation of a novel palliative care service. Mult Scler J https://doi.org/10.1177/1352458510364632.

18. Strupp J, Romtzky V, Galushko M, Golla H, Voltz R. Palliative Care for Severely Affected patients with multiple sclerosis: when and why? Results of a Delphi survey of health care Professionals. J Palliat Med. 2014. https://doi.org/10. 1089/jpm.2013.0667.

19. Bužgová $R$, Bar M, Bártová $P$, Kozáková R, Ressner $P$, Sikorová L, Zeleníková $R$ Neuropallative and rehabilitative care in patients with and advanced stage of progressive neurological diseases. Česká a Slovenská Neurologie a Neurochirurgie. 2018. https://doi.org/10.14735/amcsnn201717.

20. Giezendanner, Stéphanie, Corinna Jung, ans-Ruedi Banderet, Ina Carola Otte, Heike Gudat, Dagmar M. Haller, Bernice S. Elger, Elisabeth Zemp, and Klaus Bally. 1996. General practitioners' attitudes towards essential competencies in end-of-life care: a cross-sectional survey. PLoS One https://doi.org/10. 1371/journal.pone.0170168.

21. Willmott L, White B, Close E, Galliois C, Malcolm P, Graves N, Winch S, Callaway L, Shepherd N. Futility and the law: knowledge, practice and attitudes of doctors in end of life care. Technol Low Rev. 2016. https://doi. org/10.5204/qutlr.v16i1.622.

22. Piili RP, Metsanoja R, Hinkka H, Kellokumpu-Lehtinen P-LI, Lehto JT. Changes in attitudes towards hastened death among Finnish physicians over the past sixteen years. BMC Med Ethics. 2018. https://doi.org/10.1186/s12910018-0290-5.

23. Kaldjian LC, Jekel JF, Bernene $J$, Rosenthal GE, Vaughan-Sarrazin MS, Duffy TP. Internists attitudes towards terminal sedation in end of life care. J Med Ethics. 2004. https://doi.org/10.1136/jme.2003.004895.

24. Mercadante S, Masedu F, Mercadante A, Marinangeli F, Aielli F. Attitudes of palliative home care physicians towards palliative sedation at home in Italy. Support Care Cancer. 2017. https://doi.org/10.1007/s00520-017-3581-3.

25. Frommelt KH, Murray. The effects of death education on nurses' attitudes toward caring for terminally ill persons and their families. Am J Hospice Palliat Care. 1991. https://doi.org/10.1177/104990919100800509.

26. Mastroianni C, Peredda M, Taboga C, Mirabella F, Marfoli E, Casale G, Matarese M, Murray Frommelt KH, DeMarinis MG. Frommelt attitudes towards care of the dying scale form B: psychometric testing of the Italian version for students. OMEGA. 2015. https://doi.org/10.1177/ 0030222815568944.

27. Lewis C, Reid J, McLernon Z, Ingham Rl, Traynor M. The impact of a simulated intervention on attitudes of undergraduate nursing and medical students towards end of life care provision. BMC Palliat Care. 2016. https:// doi.org/10.1186/s12904-016-0143-2.

28. Clarke G, Fistein E, Holland A, Barclay M, Theimann P, Barclay S. Preferences for care towards the end of life when decision-making capacity may be impaired: a large scale cross-sectional survey of public attitudes in Great 
Britain and the unites states. Plos one. 2017. https://doi.org/10.1371/journal. pone. 0172104

29. Catt S, Blanchard M, Addington-Hall J, Zis M, Blizard B, King M. The development of a questionnaire to assess the attitudes of older people to end-of-life issues (AEOLI). Palliat Med. 2005. https://doi.org/10.1191/ $0269216305 \mathrm{pm} 1036 \mathrm{oa}$.

30. Park SY, Kim OS, Ma JC, Sok SR. Comparison of attitudes towards death and perceptions of do-not resuscitate orders between older Korean adults residing in a facility and home. Int J Nurs Pract. 2015. https://doi.org/10. 1111/ijn.12352.

31. Hunt K, Shlomo N, Addington-Hall J. End-od-life care and preferences for place of death among the oldest Old: Results of a Population-Based Survey using VOICES-Short Form. J Palliat Med. 2014. https://doi.org/10.1089/jpm. 2013.0385.

32. Ganzini L, Johnston WS, McFarland BH, Tolle SW, Lee MA. Attitudes of patients with amyotrophic lateral sclerosis and their care givers toward assisted suicide. N Engl J Med. 1998. https://doi.org/10.1056/ nejm199810013391406.

33. Hendl J. Qualitative research. Basic theory, methods and applications. Praha: Portál; 2016.

34. Haynes SN, Richard DS, Kubany E, S. Content validity in psychological assessment: a functional approach to concepts and methods. Psychol Assess. 1995. https://doi.org/10.1037/1040-3590.7.3.238.

35. Terwee, Caroline B., Sandra D.M. Bot, Micahel R. De Boer, Danielle A.W.M. van der Windt, Dirk L. Knol, Joost Dekker, Lex M. Bouter, and Henrica C. W. de Vet. 2007. Quality criteria were proposed for measurement properties of health status questionnaires. J Clin Epidemiol https://doi.org/10.1016/j. jclinepi.2006.03.012.

36. Peterson RA. A meta-analysis of Cronbach's coefficient alpha. Journal of consumer Research; 1994. https://doi.org/10.1086/209405.

37. Streiner DL, Norman GR. Health measurement scales: a practical guide to their development and use. 5th ed. New York: Oxford University Press; 2015.

38. Ware JE, Gandek B. Overview of the SF-36 health survey and the international quality of life assessment (IQOLA) project. J Clin Epidemiol. 1998. https://doi.org/10.1016/S0895-4356(98)00081-X.

39. Voltz R, Bernat JL, Borasio GD, Maddocks I, Oliver D, Portenoy RK. Palliative care in neurology. New York: Oxford University Press; 2004.

40. Steinhauser KE, Christakis NA, Clipp EC, et al. Factors considered important at the end of life by patients, family, physicians, and other care providers. JAMA. 2000. https://doi.org/10.1001/jama.284.19.2476.

41. Gillon R. Ethics needs principles - four can encompass the rest - and respect for autonomy should be "first among equals". J Med Ethics. 2003; 29(5):307-12.

42. Chan HM. Sharing death and dying advance directives, autonomy and the family. Bioethics. 2004;18:87-103. https://doi.org/10.1111/j.1467-8519.2004. 00383.x.

43. Helena H. Etické problémy paliativní medicíny (Ethics problems in palliative medicine). In: Vorlíček J, editor. Paliativní medicína (Palliative medicine). Praha: Aviceum; 1998.

44. Held V. The ethics of care: personal, political, and global. New York: Oxford University Press; 2005.

45. Williams MA. Practical ethics in clinical neurology. A case-based learning approach. Philadelphia: Lippincott Williams and Wilkins; 2001. https://doi. org/10.1016/j.socscimed.2008.09.037.

46. Kagan P, N. Listening: selected perspectives in theory and research. Nurs Sci Q. 2008. https://doi.org/10.1177/0894318408315027.

47. Abma TA, Oeseburg B, Widdershoven GAM, Verkerk M. The quality of caring relationships. Psychol Res Behav Manag. 2009. https://doi.org/10.2147/prbm. s4617.

48. Baldwin C. Narrative and decision-making. In O'Connor, Deborah and Barbara Purves. Decision-making, personhood and dementia: exploring the Interface. Philadelphia: Jessica Kingsley Publishers; 2009

49. Winterbottoma A, Bekkerb HL, Conner M, Mooney A. Does narrative information bias individual's decision making? A systematic review. Soc Sci Med. 2008. https://doi.org/10.1016/.socscimed.2008.09.037.

50. Bergum V, Dossetor J. Relational ethics. The full meaning of respect. Hagerstown: University Publishing Group; 2005.

51. Pollard CL. What is the right thing to do: use of a relational ethic framework to guide clinical decision-making. Int J Caring Sci. 2015;8(2):362-8.
52. ACP. End-of-life care: Guidelines for decision-making about withholding and withdrawing life-sustaining measures from adult patients. State of Queensland: Queensland Health; 2018.

53. Detering $K$, Hancock AD, Reade M, Silvester $W$. The impact of advance care planning on end of life care in elderly patients: randomised controlled trial. BMJ. 2010. https://doi.org/10.1136/bmj.c1345.

54. Cottrell L, Duggleby W. The "good death": an integrative literature review. Palliat Support Care. 2016. https://doi.org/10.1017/S1478951515001285.

55. Lynn J, Arkes HR, Stevens M, Cohn F, Koenig B, Fox E, Dawson NV, Philips RS, Hamel MB, Tsevat J. Rethinking fundamental assumptions: SUPPORT's implications for future reform. Study to understand prognoses and preferences and risks of treatment. J Am Geriatrics Soc. 2000. https://doi. org/10.1111/j.1532-5415.2000.tb03135.x

56. Teno JM, Gruneir A, Schwartz Z, Nanda A, Wetle T. Association between advance directives and quality of end-of-life care: a national study. J Am Geriatr Soc. 2007. https://doi.org/10.1111/j.1532-5415.2007.01045.x.

57. Lester D. The Collett-Lester fear of death scale: the original version and revision. Death Stud. 1990. https://doi.org/10.1080/07481189008252385.

58. Neimeyer RA, Moser RP, Wittkowski J. Assessing attitudes toward dying and death: psychometric considerations. OMEGA. 2003. https://doi.org/10.2190/ EP4R-TULM-W52G-L3EX.

59. Abdel-Khalek AM. Convergent validity of the Templer, Collett-Lester, and Arabic death anxiety scales: rejoinder. Psychol Rep. 2004. https://doi.org/10. 2466/pro.94.3c.1171-1172.

60. Tomás-Sábado J, Limonero JT, Abdel-Khalek AM. Spanish adaptation of the Collett-Lester fear of death scale. Death Stud. 2007. https://doi.org/10.1080/ 07481180601152625

61. Kolawole M, Olusegun AK. The reliability and validity of revised CollettLester fear of death scale (version 3) in Nigeria population. OMEGA. 2008. https://doi.org/10.2190/OM.57.2.e.

62. Venegas ME, Alvarado OS, Barriga O. Validation of Collett-Lester's fear of death scale in a sample of nursing students. Enfermagem: Rev. Latino-Am; 2011. https://doi.org/10.1590/S0104-11692011000500015.

63. Steptoe A, Molloy GJ, Messerli-Burgy N, Wikman A, Randall G, Perkins-Porras L, Kaski JC. Fear of dying and inflammation following acute coronary syndrome. Eur Heart J. 2011. https://doi.org/10.1093/eurheartj/ehr132.

64. Whitehead DL, Strike P, Perking-Porras L, Steptoe A. Frequency of distress and fear of dying during acute coronary syndromes and consequences for adaptation. Am J Cardiol. 2005. https://doi.org/10.1016/j.amjcard.2005.07. 070.

65. Fry S. Perceived self-efficacy domains as predictors of fear of the unknown and dear of dying among older adults. Psychol Ageing. 2003. https://doi. org/10.1037/0882-7974.18.3.474.

66. Steinhauser KE, Fitchett G, Handzo GF, Johnson KS, Koening HG, Pargament $\mathrm{Kl}$, et al. State of the science of spirituality and palliative care research part l: definitions, measurement, and outcomes. J Pain Symptom Manag. 2017. https://doi.org/10.1016/j.jpainsymman.2017.07.028.

67. Sakiko F, Yoshiuchi K, Fujita J, Sawai M, Watanabe M. Japanese People's preference for place of end-of-life care and death: a population-based nationwide survey. J Pain Symptom Manag. 2011. https://doi.org/10.1016/j. jpainsymman.2011.02.024.

68. Davison SN. End-of-life care preferences and Needs: Perceptions of Patients with Chronic Kidney Disease. Clin J Am Soc Nephrol. 2010. https://doi.org/ 10.2215/CJN.05960809.

69. Higginson IJ, Sen-Gupta GJA. Place of Care in Advanced Cancer: A qualitative systematic literature review of patient preferences. J Palliat Care. 2005. https://doi.org/10.1089/jpm.2000.3.287.

70. Hrdá K, Tolarová B. Prưvodce poskytováním paliativní péče v pobytových sociálních službách pro seniory (Guide to providing palliative care in residential social services for elder people). Praha: Centrum paliativní péče; 2015.

71. Boeteng GO, Neilands TB, Frongillo EA, Melgar-Quinonez HR, Young SL. Best practices for developing and validating scales for health, social and behavioral research: a primer. Front Public Health. 2018. https://doi.org/10. 3389/fpubh.2018.00149.

\section{Publisher's Note}

Springer Nature remains neutral with regard to jurisdictional claims in published maps and institutional affiliations. 